\title{
Simulated and Experimental Study of Single Particle Measurement Using Inductively Coupled Plasma Mass Spectrometry
}

\author{
Zishan Gong, Yan Wang, Ru Yang, Yu Yang, Xuehui Jiang, Chuanqiang Sun \\ Department of Biomedical Engineering, Precision Instrument and Optoelectronics Engineering, Tianjin University, Tianjin, China \\ Email: gongzishan820@126.com
}

\begin{abstract}
How to cite this paper: Gong, Z.S., Wang, Y., Yang, R., Yang, Y., Jiang, X.H. and Sun, C.Q. (2019) Simulated and Experimental Study of Single Particle Measurement Using Inductively Coupled Plasma Mass Spectrometry. Journal of Applied Mathematics and Physics, 7, 2723-2737.

https://doi.org/10.4236/jamp.2019.711186
\end{abstract}

Received: October 6, 2019

Accepted: November 5, 2019

Published: November 8, 2019

Copyright $\odot 2019$ by author(s) and Scientific Research Publishing Inc. This work is licensed under the Creative Commons Attribution International License (CC BY 4.0).

http://creativecommons.org/licenses/by/4.0/

\begin{abstract}
A droplet carrying particle is desolvation, vaporization, ionization, and diffusion in an inductively coupled plasma (ICP) to form a cloud of ions. It then is detected as a mass-spectrum peak of individual particle. The diameter of the particle is derived from its mass, which is calibrated using the peak area. This is the basic principle of measuring single particles using inductively coupled plasma mass spectrometry (ICP-MS). In this paper, a mathematical model describing single particles in plasma is investigated. This makes it possible to investigate the process and contributing factors of single particles measurement by ICP-MS. A series of processes are investigated, which include increasing the droplet temperature to the boiling point, desolvation of the droplets, increasing the particle temperature to the melting point, the particles are melted from a solid to the liquid, increasing the particle temperature to the boiling point, and particle vaporization. The simulation shows that both the atomic (ion) diffusion in the plasma and the incomplete vaporization of the particles are two important factors that limit the signal intensity of the particle's mass spectrum. The experiment reveals that ICP-MS is very linear for $\mathrm{Ag}$ nanoparticles below $100 \mathrm{~nm}$ and $\mathrm{SiO}_{2}$ particles below $1000 \mathrm{~nm}$. Both the simulation and experiment reveal the measurement deviation for large particles and that an increase of sampling depth can extend the diffusion time and cause signal suppression. The model can be used to study the mechanisms of monodispersed droplet or single-particle mass spectrometry, analyze the contributing parameters for single particle measurements by ICP-MS and provide a theoretical base for the optimization of single particle measurements in the practical application, such as nanoparticle devices, magnetic materials, biomedical materials additives and consumer products.
\end{abstract}




\section{Keywords}

Single Particle, Inductively Coupled Plasma Mass Spectrometry, Mathematical Model, Sample Depth

\section{Introduction}

Nanoparticles are in rapidly increasing quantities being added into not only consumer goods such as food, cosmetics, and packaging, but also into industrial products like fuel and electronics. Questions and concerns have been raised about the consequences of engineered nanoparticles (ENPs) in the ecological environment and their biological impacts [1]. As a very useful multi-element analysis tool [2] [3] [4] [5], ICP-MS is considered one of the powerful and challenging analytical approaches to assess the effect releasing of ENPs. Compared with the conventional method that is based on electron microscopy or spectrometry, ICP-MS is better suited to quickly measure the size distribution and concentration of nano- or submicron-particles. In addition, a higher analysis-speed, a more accurate qualitative analysis of multi-element particles, and a lower detection limit can be obtained with the ICP-MS method [6] [7]. A cloud of ions is formed from a droplet with single particle after desolvation, vaporization, ionization, and diffusion in the ICP. The cloud of ions from an individual particle is measured, as a single pulse, by the detector. Thus, the diameter of the particle can be derived from the mass, which is calibrated using the peak area. The number concentration of nanoparticles is proportional to the frequency of the pulses. This is the basic principle for the measurement of a single particle using ICPMS.

In 2003, Degueldre et al. [8] were the first to report highly diluted particle suspensions in an ICP using conventional nebulization to obtain the mass distribution and concentration of particles simultaneously. Since then, ICP-MS has been used for the analysis of many nanoparticles types [9]-[15]. Pace et al. [16] described a method, using a nanoparticle standard, to establish a mass-flux curve from a dissolved standard calibration. This method is especially suitable for a size analysis of these particle samples without particle standards. Several research groups used microdroplet generators (MDGs) for the size determination of nanoparticles instead of a nebulizer [17] [18] [19] [20]. Spray chamber MDGs are designed to generate individual, uniformly sized, monodisperse droplets into the plasma with $100 \%$ efficiency. Each of these produces a signal pulse that is identical to that produced by a particle of the equivalent analyte element mass. This device is also used to investigate the ICP operation condition and the fate of droplets in plasma. Olesik and his colleges [21] set up an external signal-acquisition device, coupled to an ICP-MS detector, which was operated in analog mode, to measure the size of submicron $\mathrm{SiO}_{2}$ particles. The effect of the nebulizer gas-flow rate and sample-uptake rate on the signal intensity 
is discussed. They also discovered nonlinearity in the calibration curves due to the incomplete vaporization of larger particles.

Computer modeling is very helpful to obtain a better understanding of the plasma characteristics, gas flow dynamics, and material transport in the ICP [22]. Many research groups focus on studying the ICP mechanism, and the effect of operating parameters based on a computer-assisted simulation, which has also been frequently reported. Horner et al. [23] were the first to establish mathematical models for the evaporation of aerosol droplets and the vaporization of chloride particles. They used the results of the temperature distribution in ICP and the gas-flow rate used by the simulation. Lee and Chan [24] used this model to analyze the vaporization process of gold particles in ICP. Aghaei et al. [25] discussed the effect of gas type, solvent volume, etc. on the status of the ICP using a simulation of fluid dynamics combined with an electromagnetic field.

In this paper, a mathematical model for the physical processes of droplets carrying single particles in an ICP was introduced, which makes it possible to investigate the process and contributing factors of single particles measurement by ICP-MS. A series of processes are investigated, which include increasing the droplet temperature to the boiling point, desolvation of the droplets, increasing the particle temperature to the melting point, the particles are melted from a solid to the liquid, increasing the particle temperature to the boiling point, and particle vaporization. The effects of droplet size, sampling depth, etc. on the particle size measurement of individual particles were also investigated. The simulation was compared with the experiment. This work can provide a theoretical base for the study of contributing factors and the optimization of single particle measurements using ICP-MS. We also gave the measurement range for Ag nanoparticles and $\mathrm{SiO}_{2}$ particles.

\section{Mathematical Model}

The movement of the aerosol droplets in the plasma, which carry the particles to be tested, can be simplified into several successive and relatively independent processes: increasing the droplet temperature to the boiling point, desolvation of the droplets, increasing the particle temperature to the melting point, the particles are melted from a solid to the liquid, increasing the particle temperature to the boiling point, and particle vaporization [11] [12]. The mathematical model is based on several assumptions: 1) the droplets are mainly carried in by the central channel gas, therefore they are assumed to have the same axial velocity as the gas flow at the radial center of the channel; the radial- and swirl-velocity components of the droplets are taken to be zero [23]; 2) In consideration of the low sample uptake rate for particle measurement, the solvent effect is ignored, i.e. the droplets do not affect the plasma state; 3 ) the vapor pressures below the melting point of the particles used in these studies are basically on the order of $10^{8}-10^{6} \mathrm{~atm}$, so the mass-loss caused by particle sublimation is ignored [26]; 4) the space charge effect of ions in plasma is ignored [26]. The ICP model was developed using MATLAB (2012b, Math works co. USA). 


\subsection{Heating the Droplets and Particles}

The processes include heating the droplets from room temperature to the boiling point of the solvent, heating the particles to the melting point, and heating the molten liquid to the boiling point. The temperature at the exit of the center tube is low, and the droplets reach the boiling point over a longer period of time. Both processes droplets heating and particle heating follow the heating rate formula provided by Horner et al. [23]. The heating time is calculated using the following:

$$
\begin{gathered}
\Delta T_{p}=\left(T_{g}-T_{p}\right) \cdot\left[1-\exp \left(-\frac{3 h_{c} M}{\rho r C_{p}} \cdot \Delta t\right)\right] \\
h_{c=} \frac{K_{g}}{2 r}(2+0.515 \sqrt{\operatorname{Re}})
\end{gathered}
$$

here, $\Delta T_{p}$ is the change in the surface temperature of the droplet or the particle, $T_{g}$ is the plasma gas temperature, $T_{p}$ is the surface temperature of the droplet or the particle at the beginning of the interval, $M$ is the molecular weight of the solute, $\rho$ is the density of the current phase, $r$ is the radius of the droplet or particle, $C_{p}$ is the constant-pressure heat capacity of the droplet or the molten particle, $h_{c}$ is the heat-transfer coefficient, $K_{g}$ is the gas thermal conductivity and $\operatorname{Re}$ is the Reynolds number. Considering the above assumptions, the particles move only in the axial direction, with the central gas flow at the same velocity. As a result, the Reynolds number is zero. In this model, only conduction is considered for the heat transfer between gas and solid or liquid.

\subsection{Particle Melting}

Particle melting is the process of a phase transition from solid to liquid. Based on the model assumptions, the particles do not lose mass, they only change phases. The temperature of the particles during the melting process is constant at the melting point. The time required for this process is calculated using [27].

$$
\Delta t_{\text {melt }}=\frac{2 \rho_{s} r \Delta H_{\text {fus }}}{\left(T_{g}-T_{m}\right) M h_{c}}
$$

here, $\Delta H_{\text {fus }}$ is the enthalpy of fusion of the solute material at the melting point, $\rho$ is the density of the solute, $T_{m}$ is the melting point temperature.

\subsection{Droplets Desolvation and Particles Vaporization}

During the heating process, heat from the plasma is mainly transferred to warm the droplets or particles. As the plasma temperature is high enough, the droplets or particles will reach their normal boiling point. For both desolvation and vaporization, at surface temperatures below the droplets or particles boiling point, the limiting mechanism for mass loss is probably mass transfer. When the droplets have reached their boiling point, due to the steep temperature gradient, the desolvation rate is mainly heat-transfer-limited. As solute particles possess a 
broad range of melting and boiling points, particle vaporization support both heat-transfer and mass-transfer limited kinetics.

Expressions for the heat-transfer-limited change in droplets or the particle radius with time are

$$
\begin{gathered}
r^{2}=r_{0}^{2}-k_{H T} t \\
k_{H T}=\frac{2 \pi M K\left(T_{g}-T_{p}\right)}{\rho_{l}} \cdot \frac{\ln \left(1+\Delta H_{o v} / \Delta H_{v a p}\right)}{\Delta H_{o v}} \cdot \frac{1}{\left(1+Z^{*} / r\right)}
\end{gathered}
$$

here, $r$ is the radius at time $t, r_{0}$ is the initial radius of the droplet or particle, $k_{H T}$ is the heat-transfer-limited rate constant, $\mathrm{M}$ is the molecular weight of the solute, $T_{g}$ is the plasma gas temperature, $T_{p}$ is the droplet or particle-surface temperature, $\rho_{l}$ is the density of the droplet or molten solute, $\Delta H_{\text {vap }}$ is the enthalpy of desolvation or vaporization, $\Delta H_{o v}$ is the overall heat for droplet desolvation or particles vaporization, $Z^{*}$ is a spatial scale estimate for the temperature difference between particle surface and plasma gas.

The mass-transfer-limited vaporization process results from the molecular and atomic motion caused by a difference in concentration. The expression for the mass-transfer-limited change of the particle radius with time is

$$
\frac{d r}{d t}=\frac{-M \alpha P_{s}}{\sqrt{2 \pi M R T_{g}} \rho_{l}\left(1-\frac{\alpha}{2}\right)\left(1+\frac{\alpha r}{(1-\alpha / 2) D_{12}} \cdot \sqrt{\frac{R T_{g}}{2 \pi M}}\right)}
$$

where $\alpha$ is the evaporation coefficient, set to 0.02. $P_{s}$ is the saturated vapor pressure of a droplet of particle solute, $R$ is the universal gas constant, $D_{12}$ is the diffusion coefficient of solute in the plasma gas.

\subsection{Ion Extraction by a Sampler Cone}

This model considers that vaporization and ionization occur simultaneously, and the atoms (ions) formed by vaporization are diffused due to the difference in concentration. The movement and diffusion processes of spherical atomic (ion) clouds, formed within each time step, can be calculated independently. The number of atoms released by vaporization at a certain time step can be calculated using

$$
N_{0}=\frac{4}{3} \pi\left(r_{0}^{3}-r^{3}\right) \cdot \rho \cdot N_{A} / M
$$

here, $N_{A}$ is the Avogadro number, $r_{0}$ is the radius of the particle at the beginning of the calculation, $r$ is the radius of the particle at the end of the calculation. During diffusion, after a period of time $t$, the ion concentration at radius $R$ is calculated using formula (8), $\xi$ is the degree of ionization.

$$
C_{(r, t)}=\frac{\xi N_{0}}{8\left(\pi D_{12} t\right)^{\frac{3}{2}}} \mathrm{e}^{\frac{-R^{2}}{4 D t}}
$$

The number of ions passing through the cone is statistically integrated to ob- 
tain the ion flux peak of the individual particle.

\subsection{Other Parameters}

The ICP temperature distribution data were provided by the group led by Zhiming Li [28]. More calculation parameters for MATLAB calculation are listed in Table 1.

\section{Experimental}

\subsection{Instrumentation and Parameters Set-up}

A NexION 300D ICP-MS (PerkinElmer) with the Syngistix Nano Application Module was used in this study. The time-resolved analysis (TRA) mode was used to provide temporal ICP-MS intensity profile of the target analyte. The ICP-MS was operated with nickel sampler cones, nickel skimmer cones and an aluminum hyper skimmer cone. The main instrument settings and parameters are detailed in Table 2, and the other instrument settings were the default values which were maintained throughout the study, except for a few parameter adjusted by the software during autotuning.

Table 1. Parameters setting of the model.

\begin{tabular}{|c|c|c|c|c|}
\hline \multicolumn{5}{|c|}{ Physical parameters } \\
\hline Parameter & Unit & $\mathrm{Ag}$ & $\mathrm{SiO}_{2}$ & $\mathrm{H}_{2} \mathrm{O}$ \\
\hline Solid density & $\mathrm{Kg} \cdot \mathrm{m}^{-3}$ & 10,490 & 2200 & - \\
\hline Liquid density & $\mathrm{Kg} \cdot \mathrm{m}^{-3}$ & 9320 & 2200 & 1000 \\
\hline Melting point & $\mathrm{K}$ & 1234.93 & 1983.15 & 273.15 \\
\hline Boiling point & $\mathrm{K}$ & 2435.15 & 2773.15 & 373.15 \\
\hline Molar mass & $\mathrm{g} \cdot \mathrm{mol}^{-1}$ & 107.87 & 60.08 & 18 \\
\hline Heat of fusion & $\left(\mathrm{J} \cdot \mathrm{g}^{-1}\right)$ & 104.8 & 146.44 & - \\
\hline Enthalpy of vaporization & $\left(\mathrm{J} \cdot \mathrm{mol}^{-1}\right)$ & 250,580 & 599,986 & 40,630 \\
\hline Enthalpy of atomization & $\left(\mathrm{J} \cdot \mathrm{mol}^{-1}\right)$ & - & 911,000 & - \\
\hline First ionization energy & $\mathrm{kJ} \cdot \mathrm{mol}^{-1}$ & 731 & 787 & - \\
\hline Molecule/Atom diameter & pm & 344 & 240 & 262 \\
\hline Evaporation coefficient & N/A & 0.03 & 0.02 & - \\
\hline Saturated vapor pressure & $\mathrm{Pa}$ & \multicolumn{3}{|c|}{ Calculate according to the temperature data } \\
\hline Degree of ionization & $\%$ & 91 & $85(\mathrm{Si})$ & - \\
\hline \multicolumn{5}{|c|}{ Calculation parameters } \\
\hline \multicolumn{2}{|c|}{ Parameter } & \multicolumn{3}{|c|}{ Settings } \\
\hline \multicolumn{2}{|c|}{ Calculation step } & \multicolumn{3}{|c|}{$0.1 \mu \mathrm{s}$} \\
\hline \multicolumn{2}{|c|}{ Gas movement speed } & \multicolumn{3}{|c|}{$20 \mathrm{~m} \cdot \mathrm{s}^{-1}$} \\
\hline \multicolumn{2}{|c|}{ Sampling cone diameter } & \multicolumn{3}{|c|}{$1.2 \mathrm{~mm}$} \\
\hline \multicolumn{2}{|c|}{ Sampling depth } & \multicolumn{3}{|c|}{$32-41 \mathrm{~mm}(36 \mathrm{~mm})$} \\
\hline
\end{tabular}


Table 2. Instrument parameters for PE 300 D ICP-MS.

\begin{tabular}{ccc}
\hline Parameter & Value & Units \\
\hline ICP RF power & 1600 & $\mathrm{~W}$ \\
Nebulizer gas flow & 1.00 & $\mathrm{~L} \cdot \mathrm{min}^{-1}$ \\
Auxiliary gas flow & 1.00 & $\mathrm{~L} \cdot \mathrm{min}^{-1}$ \\
Plasma gas flow & 18.00 & $\mathrm{~L} \cdot \mathrm{min}^{-1}$ \\
Analog stage voltage & -1650.00 & $\mathrm{~V}$ \\
Pulse stage voltage & 900.00 & $\mathrm{~V}$ \\
Dwell time & 100 & $\mathrm{~s}$ \\
Scan time & 100 & \\
Measurement mode & Time resolved analysis & \\
Rpq & 0.50 & \\
\hline
\end{tabular}

Daily performance was assessed (B intensity $>2000$ counts $\cdot \mathrm{s}^{-1}, \mathrm{Mg}$ intensity $>$ 15,000 count $\cdot \mathrm{s}^{-1}$, In intensity $>40,000$ counts $\cdot \mathrm{s}^{-1}$, U intensity $>20,000$ counts $\cdot \mathrm{s}^{-1}$ and Bkgd $220 \leq 1$ for $1 \mu \mathrm{g} \cdot \mathrm{L}^{-1}$ concentration with the $\mathrm{Ce}^{++} / \mathrm{Ce}$ ratio $\leq 3 \%$ and the $\mathrm{CeO} / \mathrm{Ce}$ ratio $\leq 2.5 \%)$. The analytical results were calculated using Syngistix 1.1 software.

\subsection{Reagents and Solutions}

Ultrapure water (18.2 $\mathrm{M} \Omega \mathrm{CM}$ resistivity), obtained from a Milli-Q Advanced A 10 purification system (Millipore, USA), was used to prepare all aqueous solutions for the experiments. A NexION setup solution $\left(1 \mu \mathrm{g} \cdot \mathrm{L}^{-1} \mathrm{Be}, \mathrm{Ce}, \mathrm{Fe}, \mathrm{In}, \mathrm{Li}\right.$, $\mathrm{Mg}, \mathrm{Pb}$, and $\mathrm{U}$ with $1 \% \mathrm{HNO}_{3}$, PerkinElmer, USA) was used for a daily performance check. Ag nanoparticle suspensions with the nominal particle diameters 75 (NIST, USA), 40, 60, 80, and $100 \mathrm{~nm}$ (Corpuscular, USA), $\mathrm{SiO}_{2}$ particle suspensions with the nominal particle diameters 500, 700, 800, 900, 1000, 1200, and $1500 \mathrm{~nm}$ (NIST, USA) were used in this study. The Ag nanoparticle- and $\mathrm{SiO}_{2}$ particle-suspensions were diluted to $10^{4}-10^{5}$ particles $\cdot \mathrm{mL}^{-1}$ using deionized water prior to the ICP-MS measurement. The single-element stock standard of Ag at a concentration of $1000 \mu \mathrm{g} \cdot \mathrm{mL}^{-1}$ was purchased from the National Center of Analysis and Testing for Nonferrous Metals and Electronic Materials (NCATN, China). The $50 \mu \mathrm{g} \cdot \mathrm{L}^{-1}$ aqueous Ag standard was obtained by diluting the stock solution with $1 \% \mathrm{HNO}_{3}$.

\section{Results and Discussion}

\subsection{Physical Processes of Droplets in ICP}

Length of $5 \mu \mathrm{m}$ was chosen as the typical diameter of an aerosol droplet in this model. The physical process of aerosol-droplet-carrying nanoparticles in an ICP was discussed. For $5 \mu \mathrm{m}$ aerosol-droplets carrying $100 \mathrm{~nm}$ diameter Ag nanoparticles, the physical process in an ICP is shown in Figure 1. Since the temperature at the outlet of the central tube is low, the solvent evaporate rapidly after 
the droplet has been warmed to the boiling point for a long period of time. After complete evaporation of the solvent, the particles are subjected to a process of temperature increase and phase change, which lead to complete vaporization at a distance of $25 \mathrm{~mm}$ from the outlet. The atomic (ion) cloud gradually increases in scale before it reaches the sampling cone ( $36 \mathrm{~mm}$ from the center-tube outlet) due to concentration gradients.

\subsection{Particle Peak}

$75 \mathrm{~nm}$ Ag nanoparticles were used as model particles to discuss the simulated and experimentally obtained peaks. The simulated peak was obtained by sampling the ion cloud formed by the $75 \mathrm{~nm} \mathrm{Ag}$ nanoparticle. The time was the abscissa and the normalized sampled ion number was the ordinate. The experimental peak was obtained by injecting $75 \mathrm{~nm} \mathrm{Ag}$ nanoparticle suspension, and the dwell time was set to $60 \mu$ s. The results are shown in Figure 2. It was found that the peak width of the experimental result was consistent with the simulation results, both were about $450 \mu$ s. The results are also consistent with the literature report $(300-500 \mu \mathrm{s})$ [29]. Both the experimental and simulation peaks were approximately log-normal, which is consistent with the typical particle size. However, they were not perfectly Gaussian but have a small tailing peak. This is due to both the increase in the atomic (ion) cloud scale caused by diffusion and the asymmetric peak-shape formed during the extraction process.

\subsection{Effect of Aerosol Droplet Size on Particle Measurement}

The relationship between the initial droplet size and the time required for desolvation of pure solvent droplets is obtained by simulation. The results are shown in Figure 3. For $2-22 \mu \mathrm{m}$, the time needed to increase the droplet temperature and desolvation is linearly related to the initial particle diameter, which is consistent with a previous report [30]. The deviation from linearity for the larger particles was not discussed here.

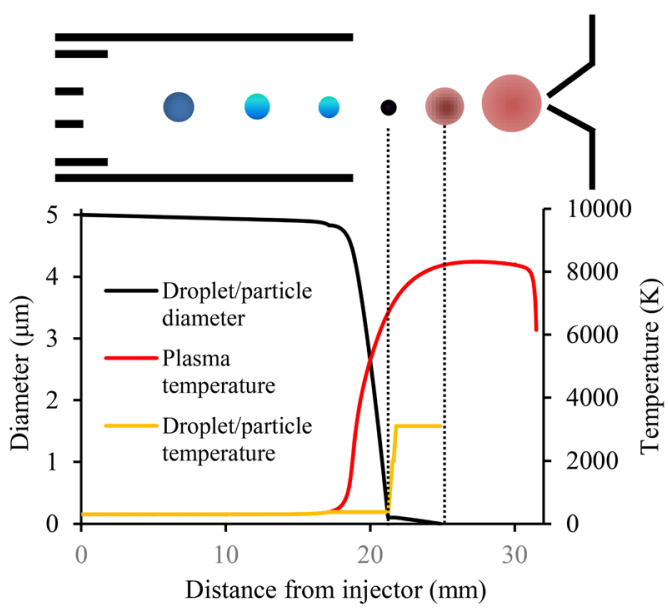

Figure 1. The physical process of $5 \mu \mathrm{m}$ aerosol drops carrying $100 \mathrm{~nm}$ Ag nanoparticles in an ICP. 


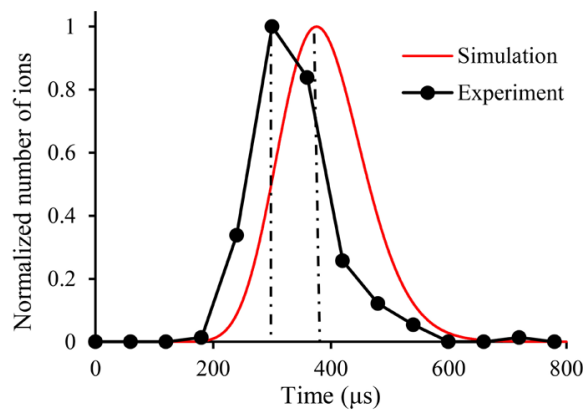

Figure 2. MS peaks of a $75 \mathrm{~nm} \mathrm{Ag}$ particle based on simulation and experiment.

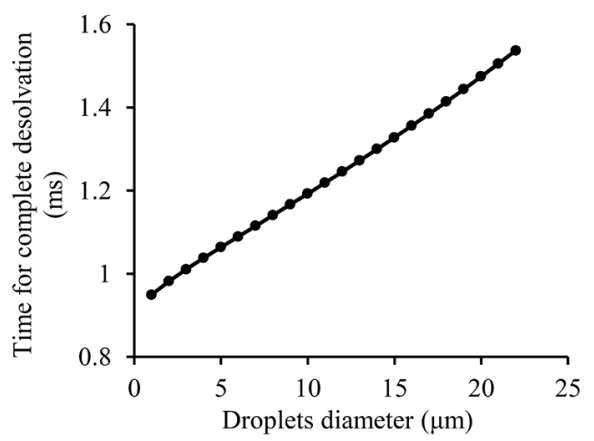

Figure 3. Effect of the initial particle diameter on desolvation time.

The time for droplet desolvation has a direct effect on the time needed to increase particle temperature and vaporization. $\mathrm{For}_{\mathrm{SiO}_{2}}$ particles with diameters of $600 \mathrm{~nm}$ and $1.5 \mu \mathrm{m}$, for example, the relationship between the ion signal intensity and the initial particle diameter was simulated for a droplet diameter from 2 to $22 \mu \mathrm{m}$. The simulation results are shown in Figure 4. It can be seen from the figures that, as the droplet size increases, the sampling-signal intensity tends to increase. This is because, when the droplet size increases, the particle vaporization start time is delayed, and the diffusion effect gradually decreases. The maximum initial droplet diameter for complete vaporization is $10 \mu \mathrm{m}$ for the $600 \mathrm{~nm}$ diameter $\mathrm{SiO}_{2}$ particle and $4 \mu \mathrm{m}$ for the $1.5 \mu \mathrm{m}$ diameter $\mathrm{SiO}_{2}$ particle, otherwise they can not completely vaporize. As the initial droplet diameter continues to increase, the signal suppression, which is caused by incomplete vaporization of the particles, becomes the main contributor, and the signal strength begins to decrease.

\subsection{Measurement Range}

The initial droplet diameter was set to $5 \mu \mathrm{m} . \mathrm{SiO}_{2}$ particles (with diameters 300 $\mathrm{nm}, 500 \mathrm{~nm}, 900$ and $1500 \mathrm{~nm}$ ) were selected to simulate the degree of vaporization before reaching the sampling cone, which is shown in Figure 5. The $\mathrm{SiO}_{2}$ particles with diameters of $300 \mathrm{~nm}$ and $500 \mathrm{~nm}$ were complete vaporized, while particles with a diameter of $900 \mathrm{~nm}$ and $1500 \mathrm{~nm}$ were incompletely vaporized ( $6 \%$ and $33 \%$ remaining, respectively). It can be seen that both measurement range and accuracy are limited by the particle diameter. 


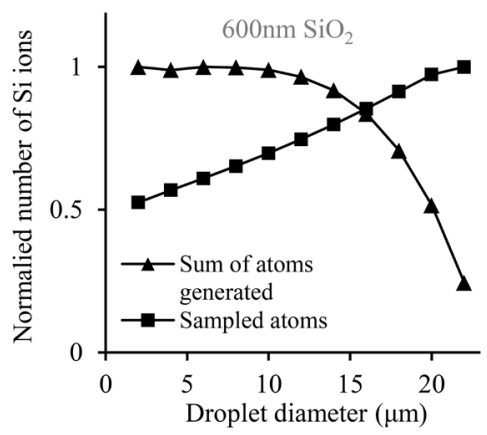

(a)

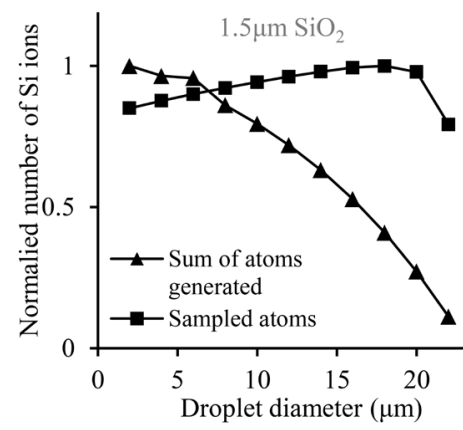

(b)

Figure 4. Simulation of the effect of initial droplet diameter on the ion signal intensity: (a) $600 \mathrm{~nm} \mathrm{SiO}_{2}$; (b) $1.5 \mu \mathrm{m} \mathrm{SiO}$.

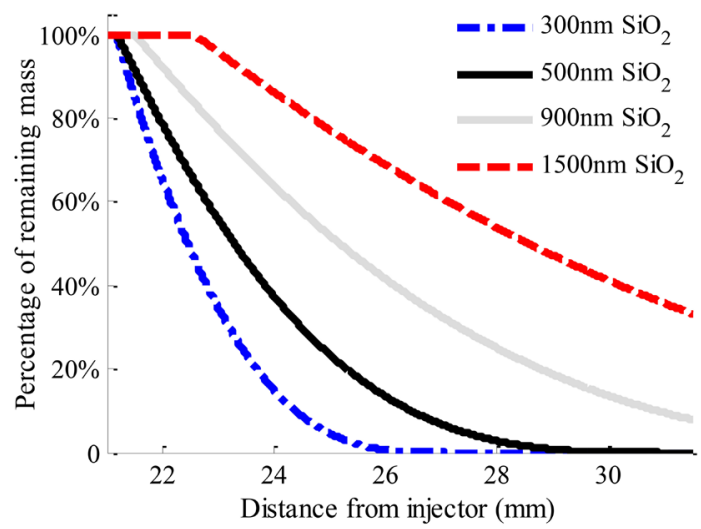

Figure 5. Degree of vaporization for $\mathrm{SiO}_{2}$ particle with different diameters.

The measurement range of $\mathrm{Ag}$ nanoparticles and $\mathrm{SiO}_{2}$ particles is studied using both simulation and experiment. The initial droplet diameter was set to 5 $\mu \mathrm{m}$. The diameters $40-100 \mathrm{~nm}$ for Ag nanoparticles and $500 \mathrm{~nm}-1500 \mathrm{~nm}$ for $\mathrm{SiO}_{2}$ particles were selected to simulate the calibration curves. The simulation results are shown in Figure 6(a) and Figure 6(c). The experimental calibration curves were drawn by injecting $\mathrm{Ag}$ nanoparticles $(40-100 \mathrm{~nm})$ and $\mathrm{SiO}_{2}$ particles $(500 \mathrm{~nm}-1500 \mathrm{~nm})$ suspension. The experimental results are shown in Figure 6(b) and Figure 6(d).

As can be seen from Figure 6, ICP-MS has good linearity for Ag nanoparticles below $100 \mathrm{~nm}$ and $\mathrm{SiO}_{2}$ particles below $1000 \mathrm{~nm}$. The experimental results are consistent with the simulation results. Both simulation and experiment show a measurement deviation for large particles. Taking the diameter of $1000 \mathrm{~nm}, 1200$ $\mathrm{nm}$, and $1500 \mathrm{~nm} \mathrm{SiO}{ }_{2}$ particles as example, the simulation results indicate that the measurement deviations are $-5.26 \%,-1.161 \%$, and $-21.22 \%$, respectively. The experimental measurement deviations for $1000 \mathrm{~nm}$ and $1500 \mathrm{~nm}$ are $-8.59 \%$ and $-14.04 \%$, respectively. Both simulation and the experiment show that the larger the particle size, the greater the measurement deviation. This is because a larger particle diameter causes a greater degree of incomplete vaporization, which is consistent with the experimental results of Chan et al. [24]. 


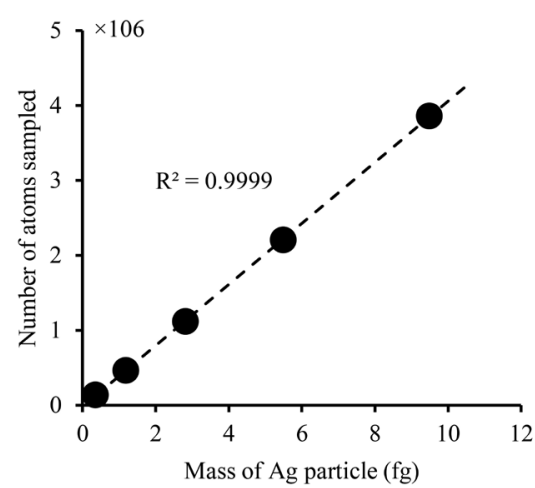

(a)

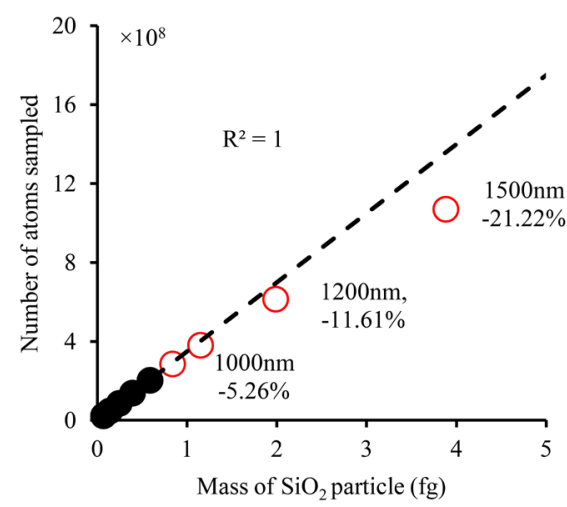

(c)

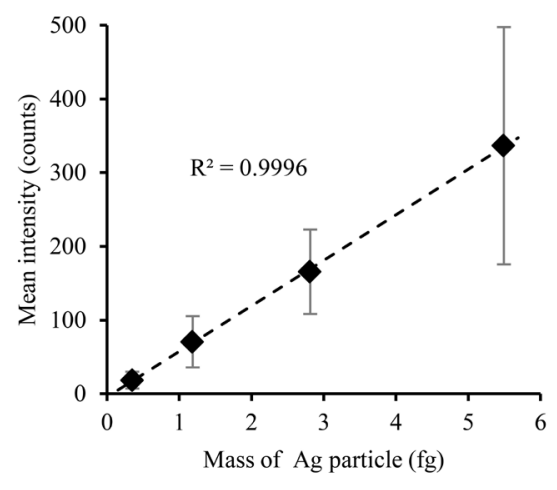

(b)

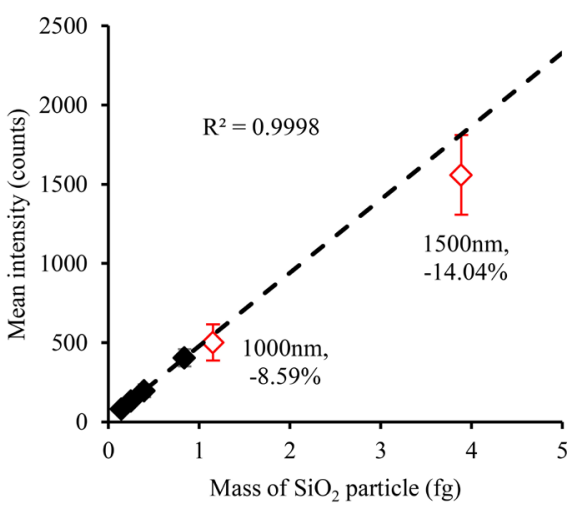

(d)

Figure 6. Simulated (a and c) and experimental (b and d) calibration curves of Ag nanoparticles ( $\mathrm{a}$ and $\mathrm{b}$ ) and $\mathrm{SiO}_{2}$ particles ( $\mathrm{c}$ and $\mathrm{d}$ ).

\subsection{Effect of Sampling Depth on Signal Intensity}

The influence of sampling depth on signal intensity is analyzed using simulation and experimental methods. $75 \mathrm{~nm} \mathrm{Ag}$ nanoparticles were selected to simulate signal strength versus sampling depth. The simulated results are shown in Figure 7(a). The signal intensity decreases with increasing sampling depth. This is because the increased sampling depth would prolong the diffusion time and cause signal suppression. Experiments were carried by measuring the signal intensity of $50 \mu \mathrm{g} \cdot \mathrm{L}^{-1}$ dissolved $\mathrm{Ag}$ ions and $75 \mathrm{~nm} \mathrm{Ag}$ nanoparticles as a function of sampling depth. The experimental results are shown in Figure $7(\mathrm{~b})$. It could be seen from the experimental results that the signal intensity of both the dissolved Ag ions and Ag nanoparticles decreases with increasing sampling depth (33- $39 \mathrm{~mm}$ ), which are consistent with the simulated results. However, in the experiment, we found that the signal-decay rate of the $\mathrm{Ag}$ nanoparticles is significantly higher than that of dissolved Ag ions. This suggests that the signal suppression, which is caused by diffusion during nanoparticle measurement, is stronger than for the dissolved ions. Pace et al. [16] [31] proposed a method to measure transmission efficiency using the ratio of solution sensitivity to NP sensitivity. Furthermore, the particle size was determined by using dissolved standards 


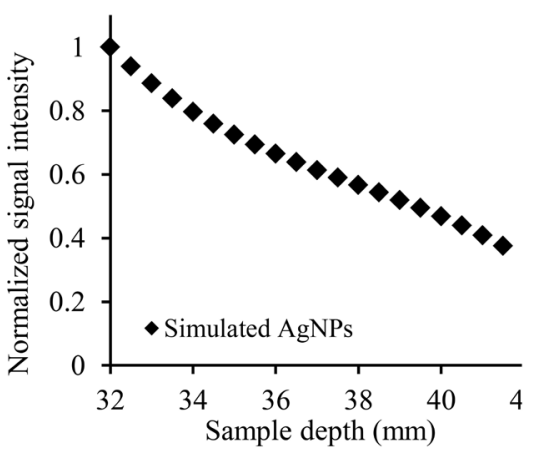

(a)

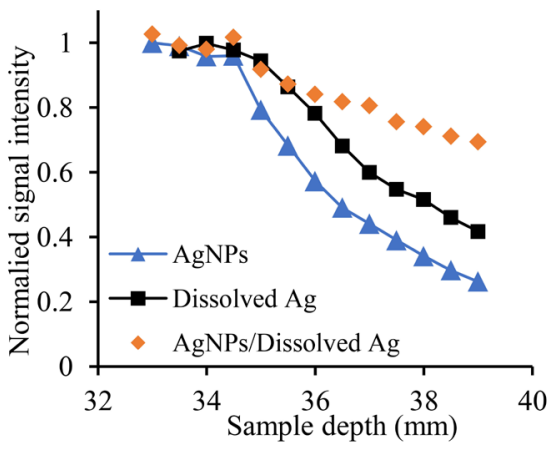

(b)

Figure 7. The effect of sample depth on the signal intensity of dissolved Ag ions and Ag nanoparticles based simulation (a) and experiment (b).

for calibration. Considering that the sampling depth has different effects on the signal intensity of dissolved ions and nanoparticles, this method might generate some errors in the calculation of transmission efficiency and particle size measurement.

\section{Conclusion}

A mathematical model for the physical process of a single aerosol particle in ICP-MS was developed. The effect of particle vaporization and ion cloud diffusion on the signal intensity of the particle was discussed. Diffusion was identified as the main reason for the asymmetry of the particle peak. Increasing the diameter of aerosol droplets can attenuate the diffusion effect within a certain range and increase signal intensity. However, a further increase of the aerosol droplet diameter can lead to the incomplete vaporization of the particles, which decreases signal intensity suppression. ICP-MS can be used for the particles-size analysis of silver nanoparticles with diameter below $100 \mathrm{~nm}$ and $\mathrm{SiO}_{2}$ particles below $1 \mu \mathrm{m}$. The experimental results are consistent with the simulated results. Because Ag nanoparticles are more affected by the sampling depth than dissolved Ag ions, this can generate errors in the calculation of the transmission efficiency and the particle-size measurement. The mathematical model described here can be used to investigate the effect of ICP parameters on a single particle measurement. In particular, it helps to study the mechanisms of monodispersed droplet or single-particle mass spectrometry, and it facilitates the optimization of the experimental conditions. Based on this model, some correction studies can also be made for particle measurements, particularly for large particles. In this study, we found that the sampling depth has different effects on the signal intensity of dissolved ions and nanoparticles, so the method using the ratio of solution sensitivity to NP sensitivity might generate some errors in the calculation of transmission efficiency and particle size measurement. In the future, a more accurate method for calculating transmission efficiency should be put forward. 


\section{Acknowledgements}

We gratefully acknowledge the key research and development plan support from Shandong province (2018YFJH0302).

\section{Conflicts of Interest}

The authors declare no conflicts of interest regarding the publication of this paper.

\section{References}

[1] Stark, W.J., Stoessel, P.R., Wohlleben, W. and Hafner, A. (2015) Industrial Applications of Nanoparticles. Chemical Society Reviews, 44, 5793-5805. https://doi.org/10.1039/C4CS00362D

[2] Cai, B., Wang, Y., Zhao, X.H. and Gong, Z.S. (2017) Multielemental Analysis of Human Serum by Dynamic Reaction Cell-Inductively Coupled Plasma-Mass Spectrometry. Analytical Letters, 50, 1-13. https://doi.org/10.1080/00032719.2016.1189928

[3] Gong, Z.-S., Jiang, X.-H., Sun, C.-Q., Tian, Y.-P., Guo, G.-H., Zhang, Y.-Z., Zhao, X.-H. and Wang, Y. (2017) Determination of 21 Elements in Human Serum Using ICP-MS with Collision/Reaction Cell. International Journal of Mass Spectrometry, 423, 20-26. https://doi.org/10.1016/j.ijms.2017.10.001

[4] Sun, C., Zhang, Y., Gong, Z., Wang, X., Yang, Y. and Wang, Y. (2018) Determination of Trace Elements in Samples with High Salt Content by Inductively Coupled Plasma Mass Spectrometry after Solid-Phase Preconcentration. International Journal of Mass Spectrometry, 431, 22-26. https://doi.org/10.1016/j.ijms.2018.04.003

[5] Gajek, R. and Choe, K.-Y. (2015) Determination of Ultra-Trace Elements in Human Plasma or Serum by ICP-MS Using Sodium in the Presence of Carbon as a Single Calibration Matrix-Match Component. Journal of Analytical Atomic Spectrometry, 30, 1142-1153. https://doi.org/10.1039/C5JA00011D

[6] Liu, J., Murphy, K.E., MacCuspie, R.I. and Winchester, M.R. (2014) Capabilities of Single Particle Inductively Coupled Plasma Mass Spectrometry for the Size Measurement of Nanoparticles: A Case Study on Gold Nanoparticles. Analytical Chemstry, 86, 3405-3414. https://doi.org/10.1021/ac403775a

[7] Lamsal, R.P., Jerkiewicz, G. and Beauchemin, D. (2018) Improving Accuracy in Single Particle Inductively Coupled Plasma Mass Spectrometry Based on Conventional Standard Solution Calibration. Microchemical Journal, 137, 485-489.

https://doi.org/10.1016/j.microc.2017.12.015

[8] Degueldre, C. and Favarger, P.Y. (2003) Colloid Analysis by Single Particle Inductively Coupled Plasma-Mass Spectroscopy: A Feasibility Study. Colloids and Surfaces A: Physicochemical and Engineering Aspects, 217, 137-142. https://doi.org/10.1016/S0927-7757(02)00568-X

[9] Laborda, F., Bolea, E. and Jimenez-Lamana, J. (2014) Single Particle Inductively Coupled Plasma Mass Spectrometry: A Powerful Tool for Nanoanalysis. Analytical Chemistry, 86, 2270-2278. https://doi.org/10.1021/ac402980q

[10] Donovan, A.R., Adams, C.D., Ma, Y., Stephan, C., Eichholz, T. and Shi, H. (2016) Single Particle ICP-MS Characterization of Titanium Dioxide, Silver, and Gold Nanoparticles during Drinking Water Treatment. Chemosphere, 144, 148-153. https://doi.org/10.1016/j.chemosphere.2015.07.081 
[11] Aznar, R., Barahona, F., Geiss, O., Ponti, J., Jose Luis, T. and Barrero-Moreno, J. (2017) Quantification and Size Characterisation of Silver Nanoparticles in Environmental Aqueous Samples and Consumer Products by Single Particle-ICPMS. Talanta, 175, 200-208. https://doi.org/10.1016/j.talanta.2017.07.048

[12] Degueldre, C. and Favarger, P.Y. (2004) Thorium Colloid Analysis by Single Particle Inductively Coupled Plasma-Mass Spectrometry. Talanta, 62, 1051-1054. https://doi.org/10.1016/j.talanta.2003.10.016

[13] Degueldre, C., Favarger, P.Y. and Bitea, C. (2004) Zirconia Colloid Analysis by Single Particle Inductively Coupled Plasma-Mass Spectrometry. Analytica Chimica Acta, 518, 137-142. https://doi.org/10.1016/j.aca.2004.04.015

[14] Degueldre, C., Favarger, P.Y., Rosse, R. and Wold, S. (2006) Uranium Colloid Analysis by Single Particle Inductively Coupled Plasma-Mass Spectrometry. Talanta, 68, 623-628. https://doi.org/10.1016/j.talanta.2005.05.006

[15] Degueldre, C., Favarger, P.Y. and Wold, S. (2006) Gold Colloid Analysis by Inductively Coupled Plasma-Mass Spectrometry in a Single Particle Mode. Analytica Chimica Acta, 555, 263-268. https://doi.org/10.1016/j.aca.2005.09.021

[16] Pace, H.E., Rogers, N.J., Jarolimek, C., Coleman, V.A., Higgins, C.P. and Ranville, J.F. (2011) Determining Transport Efficiency for the Purpose of Counting and Sizing Nanoparticles via Single Particle Inductively Coupled Plasma Mass Spectrometry. Analytical Chemistry, 83, 9361-9369. https://doi.org/10.1021/ac201952t

[17] Sabrina Gschwind, L.F., Koch, J., Borovinskaya, O., Groh, S., Niemaxc, K. and Gunther, D. (2011) Capabilities of Inductively Coupled Plasma Mass Spectrometry for the Detection of Nanoparticles Carried by Monodisperse Microdroplets. Journal of Analytical Atomic Spectrometry, 26, 1166-1174.

https://doi.org/10.1039/c0ja00249f

[18] Gschwind, S., Hagendorfer, H., Frick, D.A. and Gunther, D. (2013) Mass Quantification of Nanoparticles by Single Droplet Calibration Using Inductively Coupled Plasma Mass Spectrometry. Analytical Chemistry, 85, 5875-5883. https://doi.org/10.1021/ac400608c

[19] Borovinskaya, O., Hattendorf, B., Tanner, M., Gschwind, S. and Günther, D. (2013) A Prototype of a New Inductively Coupled Plasma Time-of-Flight Mass Spectrometer Providing Temporally Resolved, Multi-Element Detection of Short Signals Generated by Single Particles and Droplets. Journal of Analytical Atomic Spectrometry, 28, 226-233. https://doi.org/10.1039/C2JA30227F

[20] Franze, B., Strenge, I. and Engelhard, C. (2012) Single Particle Inductively Coupled Plasma Mass Spectrometry: Evaluation of Three Different Pneumatic and Piezo-Based Sample Introduction Systems for the Characterization of Silver Nanoparticles. Journal of Analytical Atomic Spectrometry, 27, 1074. https://doi.org/10.1039/c2ja00003b

[21] Olesik, J.W. and Gray, P.J. (2012) Considerations for Measurement of Individual Nanoparticles or Microparticles by ICP-MS: Determination of the Number of Particles and the Analyte Mass in Each Particle. Journal of Analytical Atomic Spectrometry, 27, 1143. https://doi.org/10.1039/c2ja30073g

[22] Bogaerts, A. and Aghaei, M. (2017) Inductively Coupled Plasma-Mass Spectrometry: Insights through Computer Modeling. Journal of Analytical Atomic Spectrometry, 32, 233-261. https://doi.org/10.1039/C6JA00408C

[23] Horner, J.A., Lehn, S.A. and Hieftje, G.M. (2002) Computerized Simulation of Aerosol-Droplet Desolvation in an Inductively Coupled Plasma. Spectrochimica Acta Part B, 57, 1025-1042. https://doi.org/10.1016/S0584-8547(02)00028-9

[24] Lee, W.-W. and Chan, W.-T. (2015) Calibration of Single-Particle Inductively Coupled 
Plasma-Mass Spectrometry (SP-ICP-MS). Journal of Analytical Atomic Spectrometry, 30, 1245-1254. https://doi.org/10.1039/C4JA00408F

[25] Aghaei, M. and Bogaerts, A. (2016) Particle Transport through an Inductively Coupled Plasma Torch: Elemental Droplet Evaporation. Journal of Analytical Atomic Spectrometry, 31, 631-641. https://doi.org/10.1039/C5JA00162E

[26] Ho, K.-S., Lui, K.-O., Lee, K.-H. and Chan, W.-T. (2013) Considerations of Particle Vaporization and Analyte Diffusion in Single-Particle Inductively Coupled PlasmaMass Spectrometry. Spectrochimica Acta Part B: Atomic Spectroscopy, 89, 30-39. https://doi.org/10.1016/j.sab.2013.08.012

[27] Horner, J.A., Chan, G.C.Y., Lehn, S.A. and Hieftje, G.M. (2008) Computerized Simulation of Solute-Particle Vaporization in an Inductively Coupled Plasma. Spectrochimica Acta Part B: Atomic Spectroscopy, 63, 217-233.

https://doi.org/10.1016/j.sab.2007.11.004

[28] Yue, D.N., Ma, Y.Y., Xu, J., Su, Y.Y., Wang, W., Yuan, X.L. and Li, Z.M. (2017) Numerical Analysis of Gas Temperature in Inductively Coupled Plasma Ion Source. Journal of Chinese Mass Spectrometry Society, 38, 521-525.

[29] Montano, M.D., Olesik, J.W., Barber, A.G., Challis, K. and Ranville, J.F. (2016) Single Particle ICP-MS: Advances toward Routine Analysis of Nanomaterials. Analytical and Bioanalytical Chemistry, 408, 5053-5074.

https://doi.org/10.1007/s00216-016-9676-8

[30] Horner, J.A. and Hieftje, G.M. (1998) Computerized Simulation of Mixed-SoluteParticle Vaporization in an Inductively Coupled Plasma. Spectrochimica Acta Part B: Atomic Spectroscopy, 53, 1235-1259. https://doi.org/10.1016/S0584-8547(98)00134-7

[31] Pace, H.E., Rogers, N.J., Jarolimek, C., Coleman, V.A., Gray, E.P., Higgins, C.P. and Ranville, J.F. (2012) Single Particle Inductively Coupled Plasma-Mass Spectrometry: A Performance Evaluation and Method Comparison in the Determination of $\mathrm{Na}$ noparticle Size. Environmental Science \& Technology, 46, 12272-12280. https://doi.org/10.1021/es301787d 